International Journal of Current Advanced Research

ISSN: O: 2319-6475, ISSN: P: 2319 - 6505, Impact Factor: SJIF: 5.995

Available Online at www.journalijcar.org

Volume 6; Issue 3; March 2017; Page No. 2866-2871

DOI: http://dx.doi.org/10.24327/ijcar.2017.2871.0128

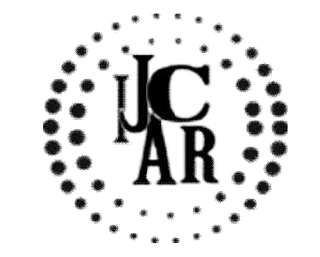

Research Article

\title{
UNDERSTANDING THE ROLE OF 'INSPIRATION PRODUCTIVITY'
}

\section{Mohamed Buheji ${ }^{1}$ and Dunya Ahmed ${ }^{2}$}

${ }^{1}$ Founder of International Institute of Inspiration Economy

${ }^{2}$ Chairwoman of International Institute of Inspiration Economy

\section{A R T I C L E I N F O}

\section{Article History:}

Received $25^{\text {th }}$ December, 2016

Received in revised form $24^{\text {th }}$ January, 2017

Accepted $14^{\text {th }}$ February, 2017

Published online $28^{\text {th }}$ March, 2017

\section{Key words:}

Inspiration Economy, Outcome Driven,

Development, Mindset, Inspiration Currency

\begin{abstract}
A B S T R A C T
Productivity, be it for individuals, organisations and/or societies have been studied very closely from the point of its role in creating definitive growth in any variables it interacts with.However,still there are scarcity in literatureabout productivity that is less dependent on resources and yet lead to radical and/or sustained competitive development.

In this paper we explore Inspiration Productivity (IP)as a new concept and investigate its ability to createrealised outcome. Thispaper is designed to show how (IP) help in creating productivity development towards an independent and interdependent socio-economy. Challenges towards transforming towards (IP) is discussed.
\end{abstract}

A small case study is taken in dormitory school to illustrate how inspiration productivity could change the targeted community outcome and desire to leave a legacy in life.

Copyright $(2017$ Mohamed Buheji and Dunya Ahmed. This is an open access article distributed under the Creative Commons Attribution License, which permits unrestricted use, distribution, and reproduction in any medium, provided the original work is properly cited.

\section{INTRODUCTION}

In 1957, George Box proposed a "method for increasing industrial productivity" which he called "Evolutionary Operation'. Box noted the similarities between the evolution of 'living things' and the advances in 'industrial processes', where both meet in fact that the need for consistent change (Box, 1957).

\section{What is Productivity?}

Productivity is defined as the relationship between the outputs generated from a system and the inputs that are used to create those outputs. Mathematically, $\mathrm{P}=\mathrm{O} / \mathrm{I}$.

OECD (2001) defines productivity as the ratio between the output volume and the volume of inputs. In other words, it measures how efficiently production inputs, such as labour and capital, are being used in an economy to produce a given level of output. Productivity is considered a key source of economic growth and competitiveness and, as such, is basic statistical information for many international comparisons and country performance assessments. For example, productivity data are used to investigate the influence of a business model and it product and labour market impact on economic performance. Productivity growth constitutes an important element for modelling the productive capacity of economies. It also allows analysts to determine capacity utilisation, which in turn allows one to gauge the position of economies in the business cycle and to forecast economic growth.

*Corresponding author: Mohamed Buheji

Founder of International Institute of Inspiration Economy

\section{The Relation between Inspiration and Productivity}

Inspiration has a unique relation with productivity since focuses on 'pull thinking' in creating proper change. Thus inspiration as per Buheji\& Thomas (2016) creates an economy that can make productivity less resource dependent and more of a type of an opportunity creator. Through inspiration productivity becomes selective and focused thus leads to competitiveness and differentiation. It is a principle that leads socio-economic behaviours to associate with a change in the mind-set towards being active to do activities from trading to focusing on abilities and capacities. (Buheji and Thomas, 2016).

Through inspiration the main framework of productivity is shifted from being driven by (supply vs. demand) to more of (capacity vs. demand). Inspiration helps to have effectiveness measures to be driven by outcome with minimal expectation reflected in what is called 'Overall Inspiration Competitiveness' (OIC).

Where OIC $=$ Availability $x$ Quality $x$ Efficiency.

OICtherefore is very important measure for transformation towards inspiration based economy. OIC is a real measure of society, community, organisations and even individual ability.Through OIC we can measure the readiness to deliver the best fitness for purpose, with the most efficient and cost effective outcome.

Since inspiration has been linked directly and indirectly for many years with job satisfaction and job performance, a positive mood, found in many studies to contribute to higher levels of productivity too (Judge et al, 2001). Inspiration 
found to cause better productivity, especially in societies where people have more opportunities and choices. Productivity has been found to be related to the feeling of having more choices since it is found to enhance the individual's reading, debating and ability to have synthesised reflections.

Inspiration raises our ability to capture opportunities that quickly go unnoticed, or occur in areas of blind spots besides raising our precision and accuracy. The challenges along with this more accuracy towards improving our achievement helps to raise the spirit of persistence.

\section{Introduction to 'Inspiration Productivity'}

Inspiration productivity is multi-functional effectiveness that reflect on people's socio-economic needs or realised functional outcomes. In an economy driven by inspiration;

Inspiration Productivity (IP) $=$ OC / I

Where, $\mathrm{OC}=$ Outcome that brings in Legacy

The formula of IP helps in shifting both organsiations and communities from growth productivity (i.e. improve with resources and projects) to development based productivity (i.e. improve with challenges and pull thinking influence). This is illustrated in Figure (1).
For inspiration productivity, effectiveness is all about the outcome not only the output measure (i.e. the level of outcome-level of quality, cost, availability, etc.).

\section{How Inspiration transforms our organisations and societies Productivity?}

Inspiration productivity (IP) is the result of managing and intervening in transformation or work processes towards specific outcome (OC); instead specific Output (O) only. Figure (2) show the preferred relations of Outcome to an input to create effective legacy.

Inspiration effectiveness is about the generation of inspiration currency that leads to outcome. The inspiration productivity measure what minimal resources were used and the use of the intrinsic powers of Individual, organisations and society (Buheji\& Ahmed, 2016).

So, in summary

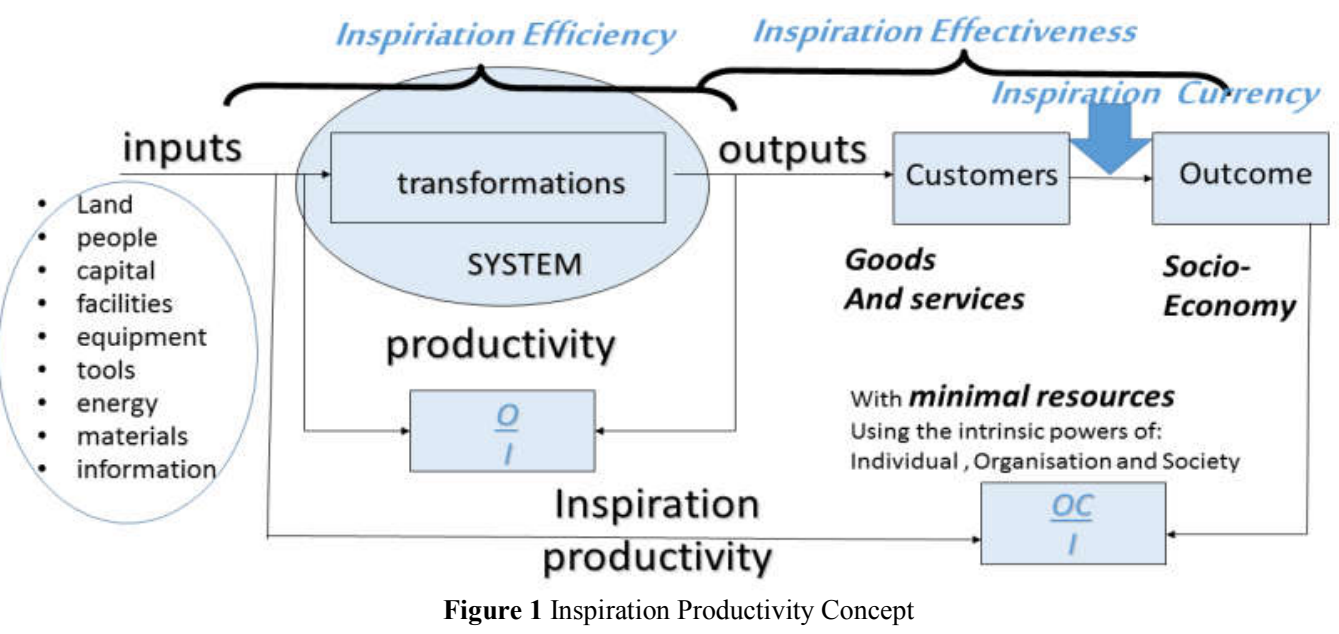

The IP is developed through the integration of inspiration spirit, inspiration opportunities and inspiration sources. This type of productivity found as per Buheji and Thomas (2016) can be delivered through experiential learning, or learning by observation and/or learning by doing.

When it comes inefficiency we normally measure it by the level of resources used to make the transformation from inputs to outputs.However, in relevance to inspiration efficiency we would go to measure even the amount of resources used in the outcome generated. Since in inspiration based economy this outcome would be based on socioeconomy. Therefore, efficiency in inspiration productivity is considered to be in practices as:

- Reduction of the resources actually be consumed in relevance to the outcome (legacy) achieved.

- On the input side of the system in relevance to the level of outcome achieved.

- In the measures of what the system sets out to accomplish (towards specific outcome) with what was actually accomplished; plan vs. actual
Full IP $=(O C / I)+$ level of Socio-Economy generated + level of minimal input of resources used + level of intrinsic powers excited.

Productivity isn't everything, but in the long run it is almost everything. A country's ability to improve its standard of living over time depends almost entirely on its ability to raise its output per worker. (Krugman, 1994).

Opposite to the concept of free market economies, knowledge economy raise the ability of the organisation and the society to more use knowledge to enhance productivity and thus creating more knowledge value added outcome. Innovation economy in the other hand raises the organisation ability to create a culture of pull thinking in productivity that leads to an effective outcome. When it comes to inspiration economy we here trying to raise the ability to discover opportunities of productivity vs. level of persistence to create (legacy) and outcome. (Hübschmann and Arceneaux, 2013). 


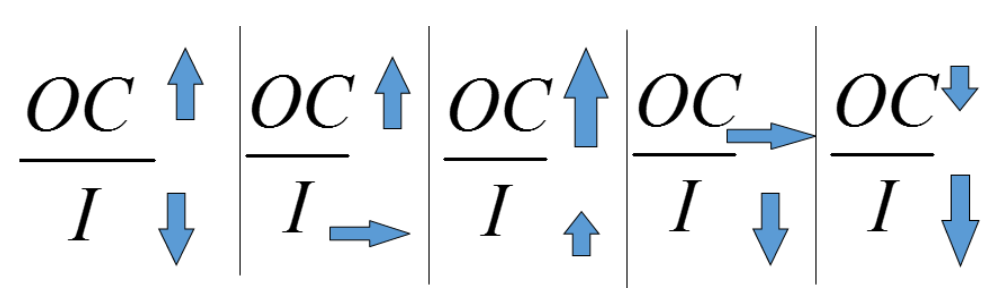

Figure 2 Preferred relations of Outcome to Input in Inspiration Productivity

Inspiration productivity focus not only in good output, but more on building the capacity of the business model to be more towards the level of forecasting high competitiveness as show in Figure (3).
We need to re-define what we mean by growth and development, with relevance to 'value added activities' and defined 'sustainable outcomes'.

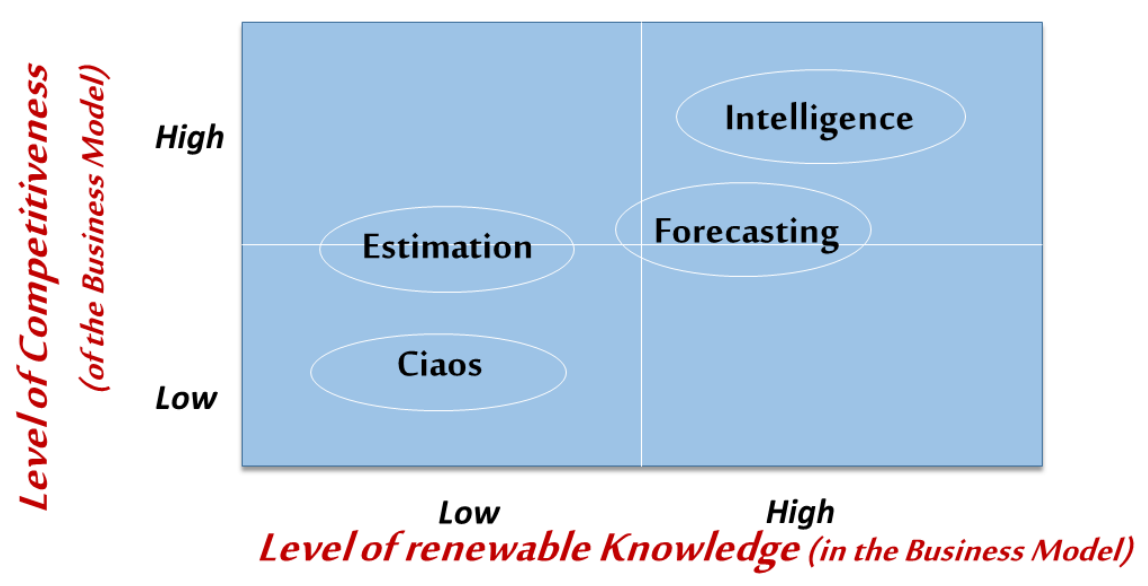

Figure 3 Shows the role of inspiration competitiveness in relevance to improving the organisation intelligence.

\section{Role of Productivity in Social Development \& Cohesion}

Carlson (1999) mentioned that stable, sustainable economic development cannot be achieved unless and until social development also takes place. Consequently, the social dimensions of economic development and productivity are as important as the economic dimensions.

Productivity and social development depend on changing human factors and targeted outcomes. Research on the social side of productivity growth and poverty reduction, for example, in developing countries by the Centre for the Study of Living Standardshas largely focused on what to do about poverty and how to compensate the poor (CSLS, 2003). In inspiration productivity the shift would be from allocating social funds to targeting anti-poverty programs that would prevent needy from being needy. It is a pro-active, positive approach to social development that aims to create a fundamental changein the business models and the community mindset again.

For inspiration productivity coexistence and competitiveness goes hand in hand. Only countries that have managed to implement and establish effective social cohesion programmes are able to bring about productive citizens that provide value added to the broader community. (Marchant, 2012).

In an inspiration productivity this means we build what we call a critical inquiring mind that loves learning and has a great directed curiosity of discovering the ability to see things from an overall viewpoint.Inspiration can be studied, more and more, as part of human behavioural research. The inquiring mind-set can then be linked to personality constructs such as 'openness' and 'change readiness'.
We need to structure the economy with 'value based thinking', while taking care of productivity and ensuring moral and qualitative value of all types of capital assets.

Development is about realised outcomes that are delivered mainly through qualitative improvements and milestones for society. If it is inspirational development, then it will be without extra resources or with minimal resources. When development occurs, our capacity develops verses the demand. Thus our capacity in production would be based on less resources, pollution and time, or even less constraints of design and delivery. Thus, development is a major source for inspirational economy differentiation.

Today more papers and evidence based books are published based on observed behaviour in relevance to social norms and preferences; including for example integrity, productivity and transparency which support the development of an established stable and sustainable socio-economic and trustworthy system. Inspiration thus can enhance the type of reciprocity that exists in our societies.

Since we are targeting a psychology based economy that focuses on better human affairs, the framework needs to show how life is rich and colourful with feelings. This will help stimulate emotions which lead to better focused motivated productivity. It is a framework that targets to make people consistently inspired to overcome the difficulty of living choices. (Sing, 1989).

It is believed that inspiration enhance a type of productivity that focus on "Appreciative Enquiry". This type of productivity can be a source for socio-economic revival for many non-productive and non-contributing societies. 
We live in an era where focused intelligent productivity is supposed to be much higher than before, due to the availability of technology, ease of transportation, better educational opportunities, etc. However, reports of certain developing countries' performance, especially in the last decade, indicate that they still have very low productivity per individual.

\section{The Power of Focused Thoughts on the Development of Inspiration Economy based Wealth}

Our thoughts seem to have a mind of their own and thus we feel on many times that we are in repetitive cycles of nonproductive thinking. It is possible, however, to redirect our thoughts towards a positive focus.

One of the challenges of self-initiated inspiration is the hidden costs of reward, where people already have a high interest in an activities results while they are getting less intrinsic inspiration in the long run (Frey and Jegen, 2001). Therefore, many psychologists believe that changing external instruments for inspiration help to explain monetary rewards, and regulating the use of punishment but proves to have little or sometimes even counterproductive effects.

When an organisation proceeds from maximizing its sales towards customer satisfaction it must give emphasis to inspiration as an aspect of service. This would help enhance the organisation goodwill in the market besides increasing its productivity.

In his best seller 'Competitive Advantage of Nations', Michael Porter (1988) mentioned that wealthy nations are the productive nations. Since productivity allows to support high wages and high returns on capital. We believe however that wealthy nations are those who can create a stable and sustainable socio-economy. If our societies are more driven by legacy creation and contribution with minimal resources they would be even more wealthy and productive. Figure (4) shows the difference between the two types of thinking.

\section{Productivity}

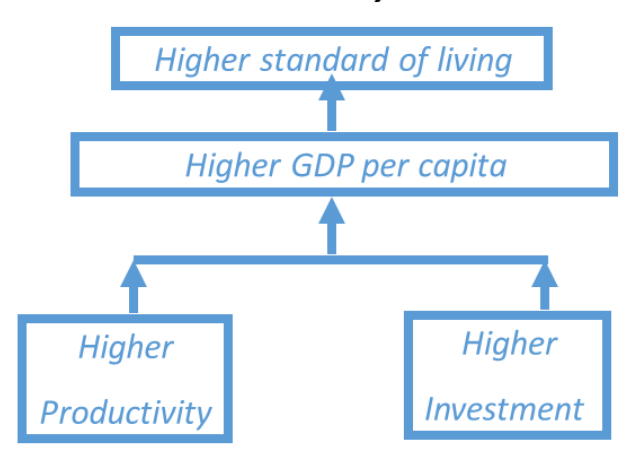

inspiration we are more able to renew business models, to be more independent $\&$ takes risks). The lab helps to make us to observe interactions"humbly'. Thus exploring and closely defining the scope while learning from interactions. The lab help us to have better visualization, codification, classification and stratification. (Saji and Ellingstad, 2016).

Competing in both high and low-cost operating environments can present a number of unique challenges (Ross and Kennedy, 2014). Inspiration Productivity help to build the constructs of inspiring mindset through selective repetition.

To give example of inspiration productivity we take the example of a humanitarian agency called Merhamet in North of Bosnia in a city called Bihac. Merhamet were supposed to feed families in need during humanitarian crisis. However, Merhamet end up committed to feeding people all year round without clear priorities to get these people out of the system and make them more independent. Through inspiration productivity program Merhamt managed in 3 months to get more than $60 \%$ of the cases.

In another can in a carpet factory in Mauritania.The inspiration productivity focused on improving the quality of life of families and their profit margin through improving the supply chain of hand-made organic products that are sold with good margin. This let to improving the quality of life different families and made the factory delay the focus on improving the productivity through automating the factory.

This shows the uniqueness of 'Pull Thinking' in inspiration driven productivity, which is being motivated by challenging problems and gathering different ideas in a short amount of time, while viewing people and things in terms of how they can be used to satisfy needs of the community or the world. Measuring "Inspiration Productivity" can be static where the $\mathrm{IP}=\mathrm{OC} / \mathrm{I}$ in a given period of time $(\mathrm{t})$. And it can be dynamic: where

\section{Inspiration Productivity}

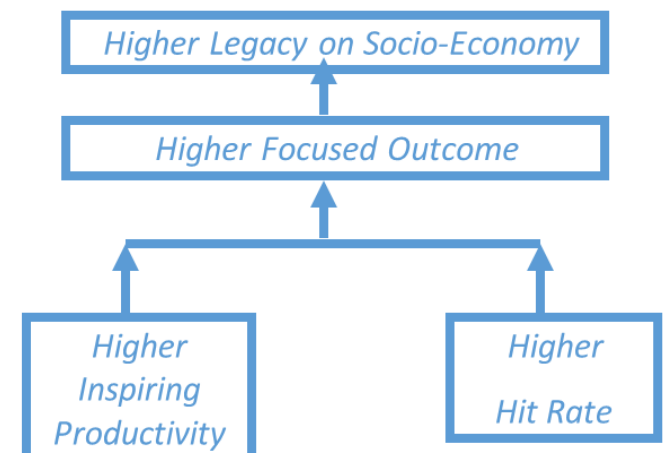

Figure 4 Shows inspiration productivity focused on creating higher socio-economic outcome through high hit rates

\section{Role of Inspiration Currency in enhancing 'Inspiration Productivity'}

IP currency measures the way individuals in a society respond to a socio-economy challenge. Currency targets to change the way individuals/organisations/ community in a society respond to a socio-economy challenge. (Buheji and Ahmed, 2016)

Inspiration labs create inspiration productivity through reinventing the business models. Through the process of
Index 1: $\quad \operatorname{IP}(1)=\mathrm{OC}(1) / \mathrm{I}(1) ; \quad \operatorname{IP}(2)=\mathrm{OC}(2) / \mathrm{I}(2) ; \quad$ then $\operatorname{IP}(2) / \mathrm{IP}(1)$ yields a dimensionless index that reflects change in inspiration productivity between periods. Then, Index 2: $((\mathrm{IP}(2)-\mathrm{IP}(1)) / \mathrm{IP}(1)) * 100$, yields the percentage change betweenInspiration Productivity queries does not just focus on doing things better. More importantly, it focus on doing selective legacy driving things better! 


\section{Factors Affecting Inspiration Productivity}

Besides education, technology, macroeconomic policies, social and culture environments, foreign aids and investments and industry policies \& competition; there are other important factors that affect any productivity, even at national level. Factors as what, why, the benefits, how, barriers and trends.Other factors affecting inspiration productivity found to be the level of learning created, the well for innovation and carrying out entrepreneurial activities with independent thinking that targets to improve thesocio-economywith limited resources.(Tsaousides, 2015).

At the national level, growing productivity leads to a higher standard of living that enhances our international competitiveness. At the national level, inspiring productivity leads to Quality of Life, help to create legacy and enhance sustainable competitiveness.

There are psychological barriers for practicing inspiration productivity. One of the early barriers is that we usually search for one 'right' answer. Also we focus on being logical or blindly following the rules. This is more challenging when we become overly specialised and we start to avoid ambiguity, fearing to look foolish or fearing mistakes and failure.

Studies, of O'Grady andRichards (2011) on inspiration in professional life, indicatethat some professionals experience inspiration through (a) a sense of calling, (b) divine guidance, (c) help in solving problems, (d) a heightening ofabilities, and (e) a fulfilling way of being. However, Gotsis and Kortezi (2008) seen that inspiration helps to improve individual's relationshipin the workplace through improving the overall work morale and their positive productivity that leads to creativity.

Given that workers from a vast array of professions are asserting that material gains are not sufficient motivation for productivity, and are calling for adescription of organizational life that stretches beyond the metaphor of a grandmoney making machine, it is reasonable to consider how organizations might systematically invite space for employees and employers to experience divine influences in their work.

Human work is a means to anend, with the end being wealth. These assumptions stem from scientific naturalism. The worldview of scientific naturalism excludes consideration of spiritualor transcendent influences in human motivation and functioning (DiClemente and Delaney 2005).

Straumea and Vitters (2012) study investigates the idea that feeling good and functioning well-being are regulated by two different mechanisms: hedonic and eudaimonic. At the state level it is assumed that happiness is a hedonic feeling typically experienced when life is easy or a goal is reached. Inspiration is a eudaimonic feeling typically experienced when facing challenges in the process of goal attainment. The distinction between the two types of positive feelings also points to another interesting paradox of organizational psychology. For the last decades, the idea that the happy worker is the productive worker has been a widespread belief. (Robertson and Cooper, 2011).

Recall that deliberate practice is a crucial ingredient indeveloping expertise, and that the practice rated asthe most important to improve performance also israted as the least enjoyable. Judging from our results, inspiration may still be a key component in productivity even if happiness decreases because inspiration motivates people to invest energy. Turning to the practical applicability of our results, organizational initiatives aimed at increasing productivity should facilitate inspiration rather than happiness, and cando so by offering challenging and complex working environments. (Straume and Vitters, 2012).

\section{Illustrating Inspiration Productivity in a School}

In order to support the influence of inspiration productivity, the researchers carried out a small case study on a dormitory school in Cazin Bosnia. The sample were carried after the students (both boys and girls) were given a workshop about inspiration economy productivity and how they can startup a small project with minimal resources to be more independent students that create jobs or be persistent to find better opportunities in their community.

Only 14 students fully answered the survey out of 30 questionnaires distributed. $14 \%$ of these students were above 18 years, the rest were between the age 14 to 18 years old only. $56 \%$ of the male students mentioned that they have been working during holidays, while none of the females have had any working experience except with helping their mothers.

$56 \%$ of the students said they have a goal in my life or they know that they can work on one now. However, only $30 \%$ of them knew what inspires them. However, $65 \%$ believed that they think now that they can participate in changing their status today.

$90 \%$ of the students participated in this survey believed that now they had a lot of good information and ideas now that can change their life. However, only $45 \%$ believed that they can change the world.

After, taking further training $90 \%$ of this students group believed they have started doing things that are important to their future. Actually, even $70 \%$ of them believed that now they can get more involved in practical topics that can change how people look at role of youth in the society. $30 \%$ of them they believe now that are persistent to achieve their goals and believe that if they fail they would get up again and again.

The inspiration productivity workshop shown to have increased the visualisation of the students in the extent of the contribution they think could give to the world. The feedback even from the school master that this group of students started to create even more positive change with their colleagues.

\section{CONCLUDING DISCUSSION}

Productivity is more likely to result from appetitive feelings like interest and inspiration as a synthesis of the literature reviewed.Inspiration productivity needs inspiring mindset that comes from critical thinking that develop the method of acting and the ability to associate things from different disciplines. This inspiring productive mindset can be developed by development of the 'spirit of inquiry' that help us to consistently renew our view of the world, re-define key inputs for improving decision making and make us more resilient to accept what we are questioned or challenge to.

Organisations and communities should take care about factors affecting inspiration productivity. This can be done through 
focusing in the creation and retrieval of inspiration currency and overcoming all the psychological barriers that prevent inspiration to flow easily.

Finally would conclude that inspiration would stay to be astrong enhancer of unique competitive productivity that focuses on 'pull thinking' that help on being selective on what to produce and when and why to produce it in relevance to a targeted outcome and legacy. However, we need to conclude too that we need more studies in this line of research area to support and illustrate the level of change that inspiration productivity creates.

\section{References}

Box, P (1957) Evolutionary operation: A method for increasing industrial productivity. Applied Statistics 6(2), pp. 81-101.

Buheji, M and Ahmed, D (2016) In Search for Inspiration Economy Currency-A Literature Review. American Journal of Industrial and Business Management, 6, 1174-1184. http://www.scirp.org/journal/ajibm ISSN Online: 2164-5175

Buheji, M and Thomas, B (2016) Handbook of Inspiration Economy. Bookboon. ISBN: 978-87-403-1318-5.

Carlson, B (1999) Social dimensions of economic development and productivity: inequality and social performance, Publication Type: Production Development 1 August 1999, Publisher: Defining and measuring productivity, Economic Commission for Latin America and the Caribbean (ECLAC)

CSLS (2003) Productivity Growth and Poverty Reduction in Developing Countries, Centre for the Study of Living Standards, CSLS Research Report 2003-06, Background Paper prepared for the 2004 World Employment Report of the International Labour Organization, http://www.csls.ca/reports/10-0305_poverty.pdf

Evan, J (1999) Inspirational Presence: The Art of Transformational Leadership, Morgan James Publishing

Frey, B. and Jegen, R. (2001) Motivation Crowding Theory. Journal of Economic Surveys, 15(5): 589-611.

Hübschmann M., Arceneaux D. (2013) 21st Century Art: The Marriage of Inspiration and Innovation. In: BrellÇokcan S., Braumann J. (eds) Rob | Arch 2012. Springer, Vienna
Judge,T; Thoresen, C; Bono,J and Patton,G (2001) The Job Satisfaction-Job Performance Relationship: A Qualitative and Quantitative Review Psychological Bulletin 2001, Vol. 127. No. 3. 376-407.

Krugman, P (1994) The Age of Diminishing Expectations. MIT Press, Third Edition.

Marchant, J (2012) In the Grand Scheme of Things: The making of inspiration through dog behaviour. FriesenPress.

OECD (2001) Measuring Productivity OECD Manual. Measurement of Aggregate and Industry-level productivity growth. https:// www. oecd.org/ std/ productivity - stats/2352458.pdf

O'Grady, K (2011) The role of inspiration in organizational life, Journal of Management, Spirituality \& Religion, 8:3, 257-272, DOI: 10.1080/14766086.2011.599148. http://dx.doi.org/10.1080/14766086.2011.599148

Porter, M (1998) The Competitive Advantage of Nations, Free Press.

Robertson, I.T. and Cooper, C.L. (2011) Well-Being: productivity and happiness at work. Basingstoke: Palgrave Macmillan

Roos, G and Kennedy, N (2014) Global Perspectives on Achieving Success in High and Low Cost Operating Environments 1st Edition, IGI Global

Saji, B and Ellingstad, P (2016) Social innovation model for business performance and innovation, International Journal of Productivity and Performance Management, Vol. 65 Issue: 2, pp.256-274, doi: 10.1108/IJPPM-102015-0147

Sing, A (1989) Industrial Productivity: A Psychological Perspective 1st Edition. SAGE Publications.

Straumea, L and Vitters, J (2012 ) Happiness, inspiration and the fully functioning person: Separating hedonic and eudaimonic well-being in the workplace, The Journal of Positive Psychology, Vol. 7, No. 5, September 2012, 387-398.

Tatebe, J (2016) Inspiration and innovation in teaching and teacher education, Journal of Education for Teaching, 42:2, 265-267.

Tsaousides, T (2015) Brainblocks: Overcoming the 7 Hidden Barriers to Success, Prentice Hall Press

\section{How to cite this article:}

Mohamed Buheji and Dunya Ahmed (2017) 'Understanding the role of 'inspiration productivity', International Journal of

Current Advanced Research, 06(03), pp. 2866-2871.

DOI: http://dx.doi.org/10.24327/ijcar.2017.2871.0128 